\title{
ASPECTOS COMPORTAMENTAIS DA REPRODUÇÃO DE DIFERENTES ESPÉCIES DE BREVIPALPUS (ACARI: TENUIPALPIDAE), EM LABORATÓRIO
}

\author{
Jeferson Luiz de Carvalho Mineiro*, Mário Eidi Sato
}

Instituto Biológico/ APTA, Centro Avançado de Pesquisa em Proteção de Plantas e Saúde Animal. Alameda dos Vidoeiros, n 1097. CEP 13101-680. Gramado, Campinas, São Paulo, Brasil. *E-mail: jefmin@hotmail.com.

\section{RESUMO}

O gênero Brevipalpus é um dos mais importantes da família Tenuipalpidae, com aproximadamente 300 espécies conhecidas, mas apenas algumas são importantes pragas na agricultura. Apesar da importância econômica de Tenuipalpidae, essa família tem sido bem menos estudada do que a Tetranychidae. Este trabalho teve como objetivo estudar os aspectos comportamentais reprodutivos de duas espécies de Brevipalpus, em laboratório. As criações de Brevipalpus papayensis Baker e Brevipalpus yothersi Baker foram conduzidas em folhas de Coffea arabica L. Foram estabelecidas colônias para diferentes espécies de Brevipalpus e cada uma foi iniciada com uma única fêmea coletada em diferentes locais. Machos de B. papayensis e de $B$. yothersi podem proteger uma deutoninfa por um breve período, para se acasalar com ela posteriormente. As fêmeas de B. yothersi ovipositam em aglomerados na nervura central ou colocam alguns ovos isolados ao longo da folha, e, após a postura, recobrem seus ovos com pequenas partículas de substrato. Foi observado na oviposição de $B$. yothersi e $B$. papayensis que os ovos formam um ângulo de $30^{\circ}$ a $45^{\circ}$ em relação à superfície da folha. Em laboratório, as fêmeas de $B$. yothersi, após a postura, levam em torno de 45 minutos no processo de proteção do ovo com partículas de areia ou gesso.

PALAVRAS-CHAVE: ácaro plano, Brevipalpus yothersi, Brevipalpus papayensis, Coffea arabica. 


\section{ABSTRACT}

\section{REPRODUCTION BEHAVIORAL IN DIFFERENT SPECIES OF BREVIPALPUS (ACARI: TENUIPALPIDAE) IN LABORATORY.}

The genus Brevipalpus is one of the most important of the family Tenuipalpidae, with approximately 300 known species, but only a few are important pests in agricul-ture. Despite the economic importance of Tenuipalpidae, this family has been far less studied than the Tetranychidae. This work aimed to study the reproductive behavioral aspects of two Brevipalpus species in the laboratory. Brevipalpus papayensis Baker and Brevipalpus yothersi Baker were reared on leaves of Coffea arabica L. Colonies were established for different species of Brevipalpus and each was started with a sin-gle female collected at different sites. Males of $B$. papayensis and $B$. yothersi can pro-tect a deutoninfa for a short time to mate with it later. The females of $B$. yothersi tend to reuse the same ovipositional sites, the eggs are often clustered together or lay some isolated eggs along the leaf, and after laying, cover their eggs with small particles. We observed that in the oviposition of $B$. yothersi and $B$. papayensis, the eggs form an an-gle of $30^{\circ}$ to $45^{\circ}$ with respect to the surface of the leaf. In the laboratory, females of $B$. yothersi after laying, take about 45 minutes in the egg protection process with particles of sand or gypsum.

KEYWORDS: flat mites, Brevipalpus yothersi, Brevipalpus papayensis, Coffea arabica.

O gênero Brevipalpus é um dos mais importantes da família Tenuipalpidae, com aproximadamente 300 espécies conhecidas (MESA et al., 2009), mas apenas algumas são importantes pragas na agricultura, incluindo Brevipalpus californicus (Banks), Brevipalpus obovatus Donnadieu, Brevipalpus lewisi McGregor (CHILDERS et al., 2003a e 2003b; HOY, 2011).

Apesar da importância econômica de Tenuipalpidae (ácaros também conhecidos como ácaros planos), essa família tem sido bem menos estudada do que a Tetranychidae em termos comportamen- tais (JEPPSON et al, 1975; CHILDERS et al., 2003a e 2003b; GERSON, 2008; HOY, 2011). O conhecimento sobre a biologia e os métodos integrados de controle de tenipalpídeos é relativamente ínfimo (JEPPSON et al., 1975; CHIAVEGATO, 1986; OLIVEIRA, 1986; CHIAVEGATO, KHARFAN, 1993; MORAES, FLECHTMANN, 2008; GERSON, 2008).

Depois da revisão dos ácaros do complexo phoenicis, realizada por BEARD et al. (2015) e MINEIRO et al. (2018), vários levantamentos foram realizados, em diferentes espécies botânicas, em especial Coffea spp., no estado de São Paulo. 
Duas espécies foram encontradas até o momento: Brevipalpus papayensis Baker e Brevipalpus yothersi Baker em diferentes localidades (MINEIRO et al., 2014, 2015, 2016). Este trabalho teve como objetivo estudar os aspectos comportamentais de reprodução dessas duas espécies de Brevipalpus, em laboratório.

A criação de diferentes espécies de Brevipalpus foi realizada em arenas sobre folhas de Coffea arabica L., no Laboratório de Acarologia, do Instituto Biológico, em Campinas, SP. As folhas de cafeeiro foram lavadas em água corrente, secas, eliminando-se, em seguida, qualquer estágio de desenvolvimento de Brevipalpus ou de outros ácaros provenientes do campo.

Foram estabelecidas colônias de diferentes espécies de Brevipalpus e cada uma foi iniciada com uma única fêmea coletada em diferentes locais (Tabela 1). O ensaio teve início em dezembro de 2012 e foram estudadas 19 linhagens, sendo 9 de $B$. yothersi e 10 de $B$. papayensis. As diferentes populações e espécies de Brevipalpus foram mantidas em sala climatizada, com temperatura de $25 \pm 2{ }^{\circ} \mathrm{C}$, umidade relativa de $70 \pm 5 \%$ e fotofase de 14 horas, no Laboratório de Acarologia, do Instituto Biológico, em Campinas, SP.

As populações originais de B. papayensis e $B$. yothersi foram obtidas de plantas de C. arábica e Coffea canephora Pierre ex Froehner. As folhas de cafeeiro foram colocadas com face adaxial voltada para cima, sobre uma camada (1 $\mathrm{cm}$ ) de espuma de poliuretano umede- cida com água, em bandeja de plástico. O pecíolo e a borda de cada folha foram recobertos por uma tira de algodão, para manter as folhas em boas condições por até 20 dias, quando foram substituídas. Ao centro da folha foi pincelada uma mistura de gesso + areia, para proporcionar local de abrigo e oviposição para as fêmeas.

A observação da postura foi realizada com auxílio de estereomicroscópio com aumento de 60 vezes, em arenas de criação mantidas no laboratório. Fêmeas de $B$. papayensis e $B$. yothersi foram observadas do momento da postura na folha até o final do processo de proteção do ovo. Para tanto, foi utilizado um cronômetro e anotada toda a movimentação e o tempo para cada atividade.

\section{Comportamento reprodutivo}

Foi observado o comportamento de machos de Brevipalpus em relação às fêmeas adultas e deutoninfas. Machos de $B$. papayensis e de $B$. yothersi podem proteger uma deutoninfa por um breve período para se acasalar com ela posteriormente (Figuras 1A e 1B), mas não foram observados ácaros esperando pela fêmea adulta recém-emergida. Ao que parece, o macho desiste e sai à procura de fêmeas adultas. Esse tipo de comportamento, de proteção da deutoninfa, já tem sido exaustivamente observado, principalmente em Tetranychus urticae Koch (CONE et al., 1971a, 1971b; PENMAN,CONE, 1972; POTTER et al., 1976). Essa é a primeira vez que se observa esse tipo de comportamento 
para B. papayensis e B. yothersi. Como nas arenas geralmente havia, no máximo, dois machos e esses praticamente não disputavam a mesma deutoninfa, não se constatou nenhum comportamento agressivo de guarda da mesma ou de outra fêmea que porventura ficasse próxima do casal.

Além disso, o que parece ser mais frequente, é que os machos procuram por fêmeas adultas para acasalar. Aparentemente, eles procuram por fêmeas adultas de qualquer idade, ou seja, desde as recém-emergidas até as com mais idade. O macho se posiciona na fêmea por baixo, logo na porção terminal do corpo, onde ele a segura com os dois primeiros pares de pernas. Os dois últimos pares de pernas ficam apoiados no substrato. A parte posterior do macho é recurvada e se posiciona na fêmea, onde é feita a transferência do esperma (Figura 2). O comportamento de cópula e transferência de esperma também foram observados por ALBERTI et al. (2014), onde detalham minuciosamente a anatomia e as estruturas internas do sistema reprodutivo do macho de Brevipalpus.

\section{Comportamento de oviposição}

As fêmeas de $B$. yothersi ovipositam em aglomerados na nervura central ou colocam alguns ovos isolados ao longo da folha, e, após a postura, recobrem seus ovos com pequenas partículas de gesso (Figuras $3 \mathrm{~A}$ e $3 \mathrm{~B}$ ), quando o ovo é colocado junto à porção de gesso e areia. No caso do ovo ser colocado fora dessa região, ou seja, em qualquer ou- tra parte da folha, esse não é recoberto por falta de material particulado. Folhas de cafeeiro coletadas no campo foram examinadas e verificou-se que os ovos de $B$. yothersi também eram colocados próximos à nervura central, aglomerados e recobertos com partículas de areia ou outro material disponível. Em alguns casos, o material era tão grande que parecia ser maior que o corpo do ácaro (Figura 3C). Ovos colocados isolados e espaIhados pela superfície da folha também eram recobertos por partículas de areia, tornando-o praticamente invisível, com tanto material sobreposto (Figura 3D).

Já as fêmeas de $B$. papayensis não recobrem seus ovos como as espécies anteriores. Mesmo estando os ovos junto ao gesso + areia, esses permanecem limpos. Várias fêmeas colocam seus ovos junto a outros (Figuras 4A e 4B).

Foi observado que os ovos de $B$. yothersi e B. papayensis, ao serem colocados, formam um ângulo de $30^{\circ}$ a $45^{\circ}$ em relação à superfície da folha.

CHIAVEGATO (1986) verificou que a fêmea geralmente deposita seu ovo em locais abrigados, tais como fendas nas folhas ou nos frutos, em lesões de qualquer natureza e escamas de cochonilhas, envolvido nas próprias exúvias ou em grânulos de poeira. Embora os ovos sejam depositados individualmente, parece haver certa tendência de que novos ovos sejam colocados em locais onde já havia uma postura anterior. Em observação de material vindo do campo, esses ácaros também fazem postura nos ramos, principalmente na parte mais nova. 
Em laboratório, as fêmeas de $B$. yothersi, após a postura, levam em torno de 45 minutos no processo de proteção do ovo com partículas de areia ou gesso (Figura 5). Nos dois primeiros minutos dão voltas ao redor do ovo, parecendo procurar algum material para protegê-lo. No terceiro minuto, as voltas ao redor do ovo são mais amplas. Ao encontrar a partícula de gesso ou areia mais adequada para recobrir o ovo, pegam-na com o tarso I ou II, geralmente da perna esquerda. Também foi observado que em algumas poucas fêmeas as pernas I e II da direita são utilizadas para pegar partículas de areia ou gesso. A partícula fica aderida em um dos tarsos ou até mesmo em alguns casos nos dois tarsos. Essa perna é, então, suspensa acima do corpo e ela caminha até o ovo, onde posiciona o material. Ao passar sobre o ovo, recoberto com as partículas de areia ou gesso, essas não se aderem ao corpo e nem nas pernas das fêmeas. Após o $17^{\circ}$ minuto a fêmea se distancia mais do ovo. Agora, as voltas não são circulares, mas irregulares, não parecendo ter um padrão definido. A partir desse momento, os movimentos são mais agitados, mas sempre trazendo alguma partícula para proteger o ovo. A partir do $26^{\circ}$ minuto, ao aproximar-se do ovo, a fêmea fica tateando-o freneticamente com os dois primeiros pares de pernas. Aos 37 minutos, a fêmea sai novamente à procura de mais partículas e distancia-se mais ainda. Nesse momento, aparentemente desorientada, parece perder o local da postura. Como ela tem uma partícula no tarso, que seria para recobrir o ovo, essa é deixada de lado e ela volta a usar todas as pernas para se locomover. Próxima à postura dessa primeira fêmea, outra fez a postura e deu início ao recobrimento do ovo. A primeira fêmea então se aproxima e se posiciona sobre esse ovo e parece querer ajudar a segunda fêmea a recobrir o ovo também. Mas a segunda fêmea aparentemente não quer a ajuda, desloca a primeira e continua sozinha no processo de recobrimento do ovo. A primeira, então, se afasta, caminha pela folha e começa a se alimentar.

Esse tipo de comportamento não foi constatado em fêmeas de $B$. papayensis, ou seja, ela não faz nenhum tipo de proteção para seus ovos. As fêmeas de B. papayensis, após a postura, dão uma volta ao redor do ovo e param por alguns instantes. Esse comportamento, entre a volta no ovo e a parada para "descanso", leva em torno de 60 segundos. Algumas fêmeas podem permanecer até mais de 120 segundos paradas depois da volta ao redor do ovo. Depois disso, as fêmeas saem caminhando pela folha.

Esse comportamento já havia sido constatado por HARAMOTO (1969), em estudos sobre a biologia de "B. phoenicis", em frutos verdes de mamão. Esse autor observou que, quando está pronta para oviposição, a fêmea procura um local adequado, tal como uma exúvia, uma fenda na superfície da planta ou a axila de um broto para a deposição do ovo. Após a postura, a fêmea deixa o local de oviposição e, nas proximidades, retoma o processo de alimentação até 
que outro ovo esteja pronto para ser colocado. Como a fêmea geralmente volta ao mesmo local, para nova oviposição, e, frequentemente, várias fêmeas ovipositam num mesmo local, pode-se muitas vezes encontrar vários ovos agregados em massa. Esses ovos são depositados igualmente durante o dia e a noite.

Observações semelhantes foram constatadas no presente trabalho, ou seja, a fêmea procura local adequado para a postura e outras fêmeas também fazem posturas junto a outros ovos. Porém, não foi possível confirmar se a mes- ma fêmea torna a fazer novas posturas junto ao primeiro ovo e tão pouco posturas noturnas.

Este estudo é o primeiro a abordar os aspectos comportamentais de espécies de Brevipalpus, evidenciando, assim, alguns padrões de comportamento diferentes entre essas espécies. Sem sombra de dúvidas, há necessidade de se realizar estudos comportamentais, ecológicos e taxonômicos mais detalhados para se aprofundar os conhecimentos sobre esses ácaros.

\section{AGRADECIMENTOS}

À FAPESP, pela concessão de bolsa de Pós-Doutorado ao primeiro autor (Processo FAPESP: 2012/14268-2) e pelo financiamento dessa pesquisa (Processos \#2017/50334-3 e 2016/06919-4). À Embrapa-Café (Consórcio Pesquisa Café), pela bolsa ao primeiro autor. Ao CNPq, pela bolsa produtividade ao segundo autor. À PqC Dalva Gabriel, do Instituto Biológico, pela revisão do manuscrito. 


\section{REFERÊNCIAS}

ALBERTI, G.; TASSI, A.D.; KITAJIMA, E.W. Anatomy and Fine Structure of Brevipalpus Mites (Tenuipalpidae) - Economically Important Plant-Virus Vectors - Part 5: Male Reproductive System. Zoologica, v.160, p.113-144, 2014.

BEARD, J.J.; OCHOA, R.; BRASWELL, W.E.; BAUCHAN, G.R. Brevipalpus phoenicis (Geijskes) species complex (Acari: Tenuipalpidae) - a closer look. Zootaxa, v.3944, n.1, p.1-67, 2015.

CHIAVEGATO, L.G. Biologia do ácaro Brevipalpus phoenicis em citros. Pesquisa Agropecuária Brasileira, v.21, n.8, p. 813-816, 1986.

CHIAVEGATO, L.G.; KHARFAN, P.R. Comportamento do ácaro da leprose Brevipalpus phoenicis (G.) (Acari: Tenuipalpidae) em citros. Anais da Sociedade Entomológica do Brasil, v.22, n.2, p. 355-359, 1993.

CHILDERS, C.C.; FRENCH, J.V.; RODRIGUES, J.C.V. Brevipalpus californicus, B. obovatus, B. phoenicis and B. lewisi (Acari: Tenuipalpidae): a review of their biology, feeding injury and economic importance. Experimental and Applied Acarology, v.30, p.5-28, 2003a.

CHILDERS, C.C.; RODRIGUES, J.C.V.; WELBOURN, W.C. Host plants of Brevipalpus californicus, B. obovatus, and B. phoenicis (Acari: Tenuipalpidae) and their potential involvement in the spread of viral diseases vectored by these mites. Experimental and Applied Acarology, v.30, p.29-105, 2003b.

CONE, W.W.; MCDONOUGH, L.M.; MAITLEN, J.C.; BURDAJEWIC, Z. Pheromone studies of the two spotted spider mite. I. Evidence of a sex pheromone. Journal of Economic Entomology, v.64, p.355-358, 1971a.

CONE, W.W.; PREDKI, S.; KLOSTERMEYER, E. Pheromone studies of the two spotted spider mite. II. Behavioral response of males to quiescent deutonymphs. Journal of Economic Entomology, v.64, p. 379-382, 1971 b.

GERSON, U. The Tenuipalpidae: An underexplored family of plant-feeding mites. Systematic and Applied Acarology, v.13, p.82-101, 2008.

HARAMOTO, P.H. Biology and control of Brevipalpus phoenicis (Geijskes) (Acarina: Tenuipalpidae). Honolulu, Hawaii Agriculture Experimental Station. Technical Bulletin, $\mathrm{N}^{\circ}$ 68, 63p. 1969.

HOY, M.A. Agricultural Acarology - Introduction to integrated mite management. CRC Press. Taylor \& Francis Group. 2011. 410p.

JEPPSON, L.R.; KEIFER, H.H.; BAKER, E.W. Mites injurious to economic plants. Berkley: University of California Press. 1975. 614p. 
MESA, N.C.; OCHOA, R.; WELBOURN, W.C.; EVANS, G.A.; MORAES, G.J. DE. A catalog of the Tenuipalpidae (Acari) of the world with a key to genera. Zootaxa, v.2098, p.1-185, 2009.

MINEIRO, J.L.C.; OCHOA, R.; SATO, M.E. Distribution of Brevipalpus papayensis Baker (Acari: Tenuipalpidae) in different host plants and locations in the State of São Paulo. In: 8th SYMPOSIUM OF THE EUROPEANASSOCIATIONOFACAROLOGISTS, 2016. Valência, Espanha. Resumos... Universidade Politécnica de Valência, p.84.

MINEIRO, J.L.C.; SATO, M.E.; NOVELLI, V.M. ; ANDRADE, D.J. Distribuição de Brevipalpus yothersi Baker, 1949 (Acari: Tenuipalpidae) em diferentes hospedeiras e localidades no estado de São Paulo. In: Reunião Anual do Instituto Biológico, 2015, São Paulo. Resumos ....O Biológico, v.77, p.84, 2015.

MINEIRO, J.L.C.; SATO, M.E.; OCHOA, R.; NOVELLI, V.M.; NUNES, M.A.; FERREIRA, P.R. Brevipalpus phoenicis (group species B) on Citrus spp. and Coffea arabica, State of São Paulo, Brazil. In: XIV International Congress of Acarology, 2014, Kyoto. Resumos...Abstract book. Kyoto, 2014. p.108.

MINEIRO, J.L.C.; SATO, M.E.; OCHOA, R.; BEARD, J.; BAUCHAN, G. Revisão taxonômica do ácaro da leprose dos citros e sua distribuição no Brasil. Citrus Research \& Technology,v.39, p.1-11, 2018.

MORAES, G.J.; FLECHTMANN, C.H.W. Manual de Acarologia - Acarologia básica e ácaros de plantas cultivadas no Brasil. Ribeirão Preto. Holos Editora. 2008. 288p.

OLIVEIRA, C.A.L. de. Flutuação populacional e medidas de controle do ácaro da leprose Brevipalpus phoenicis (Geijskes, 1939) em citros. Laranja, v.8, p.1-31, 1986.

PENMAN, D.R.; CONE, W.W. Behavior of male two-spotted spider mites in response to quiescent female deutonymphs and two web. Annals of the Entomological Society of America, v.65, p.1289-1293, 1972.

POTTER, D.A.; WRENSCH, D.L.; JOHNSTON, D.E. Guarding, aggressive behavior and mating success in male two-spotted spider mites. Annals of the Entomological Society of America, v.68, p.707-711, 1976. 
Tabela 1. Linhagens de diferentes espécies de Brevipalpus coletadas em diferentes hospedeiras e mantidas no Laboratório de Acarologia, do Instituto Biológico, em Campinas, SP.

\begin{tabular}{lll} 
Local de origem & Planta hospedeira & Espécie \\
\hline Atibaia - SP & C. arabica cv. Catuaí Amarelo & B. papayensis \\
Brodowski - SP & C. arabica & B. yothersi \\
Campinas (IB) - SP & C. arabica & B. papayensis \\
Campinas (IB) - SP & C. arabica & B. yothersi \\
Campinas (IB) - SP & C. canephora & B. yothersi \\
Campinas (IAC) - SP & C. arabica cv. Mundo Novo & B. yothersi \\
Campinas (IAC) - SP & C. canephora cv. Apoatã & B. papayensis \\
Campinas (IAC) - SP & C. dewevrei var. Excelsa & B. papayensis \\
Cordeirópolis (Citricultura) - SP & C. arabica & B. yothersi \\
Cordeirópolis (Citricultura) - SP & C. arabica & B. papayensis \\
Cordeirópolis - SP (Faz. Ibicaba) & C. arabica & B. yothersi \\
Curitiba - PR & C. arabica & B. papayensis \\
Garça - SP & C. arabica & B. papayensis \\
Monte Alegre do Sul - SP & C. arabica & B. papayensis \\
Monte Santo de Minas - MG & C. arabica & B. yothersi \\
Presidente Prudente - SP & C. arabica & B. yothersi \\
São Bento do Sapucaí - SP & C. arabica & C. arabica \\
São Paulo (IB) - SP & C. arabica & B. papayensis \\
Vera Cruz - SP & & B. yothersi \\
\hline
\end{tabular}

Obs.: IB = Instituto Biológico; IAC = Instituto Agronômico de Campinas;

Citricultura $=$ Centro de Citricultura do Instituto Agronômico de Campinas . 


\section{LISTA DAS FIGURAS}
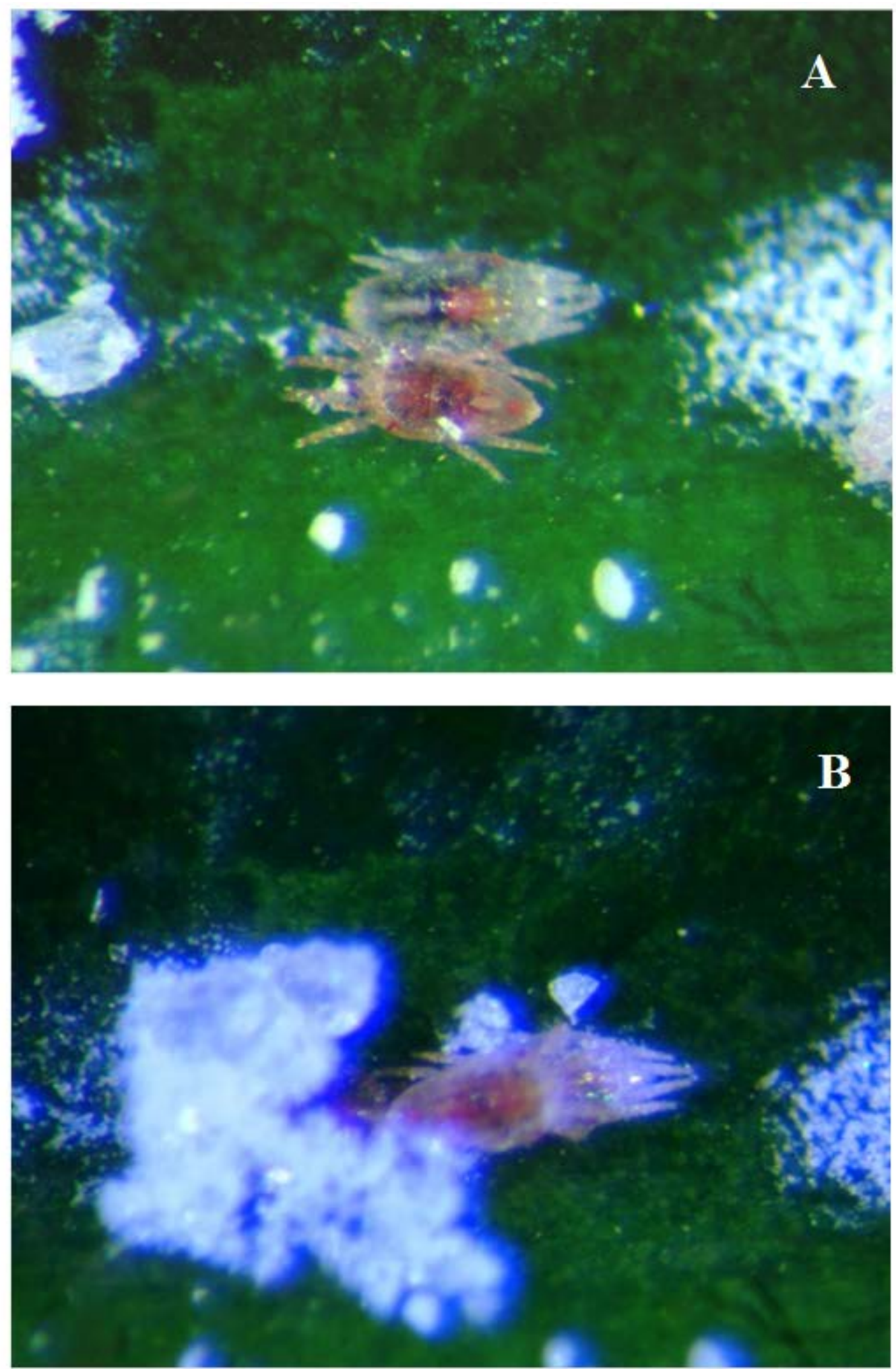

Figura 1. Macho adulto de Brevipalpus papayensis guardando deutoninfa. 


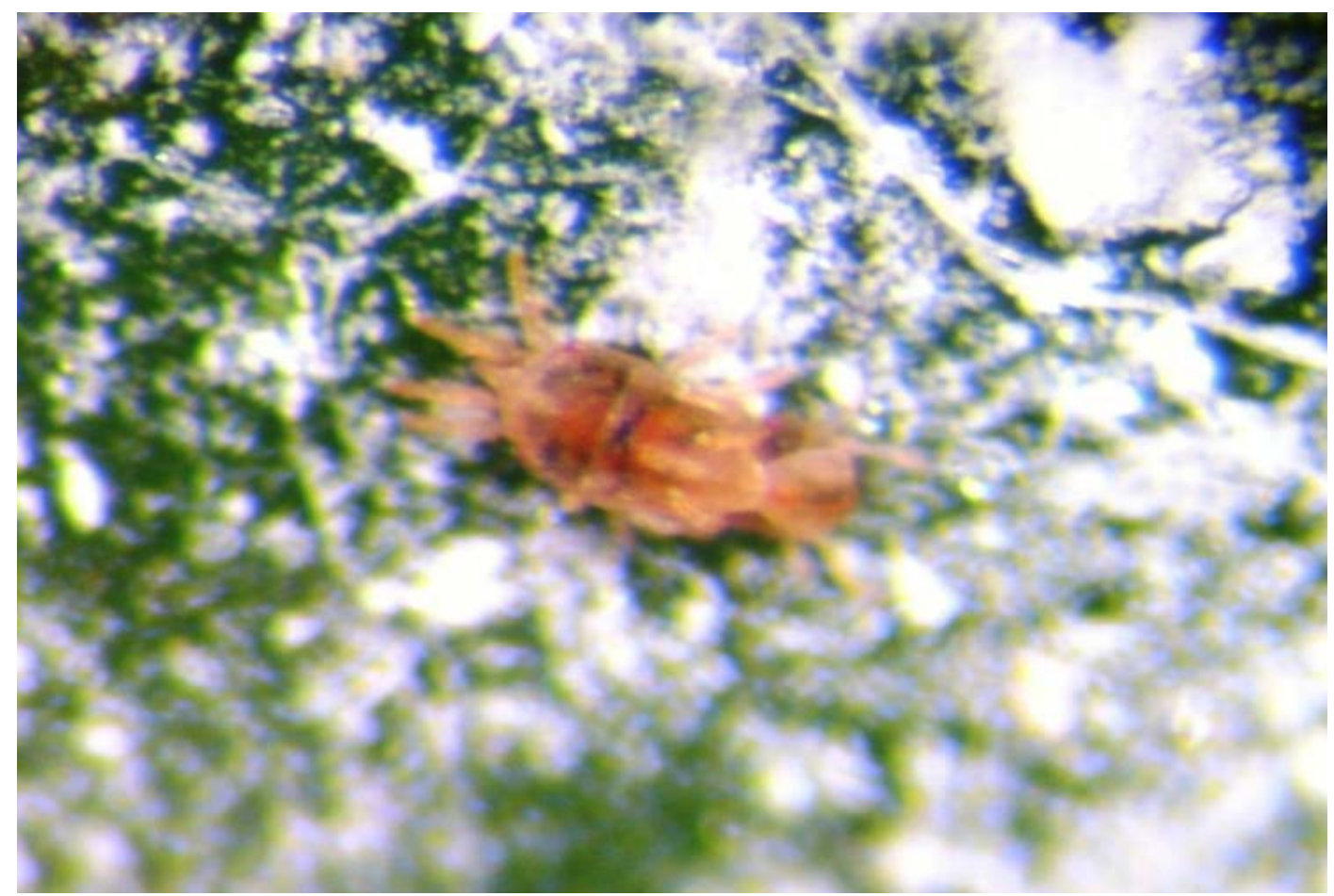

Figura 2. Acasalamento de Brevipalpus yothersi. Macho sob a fêmea.
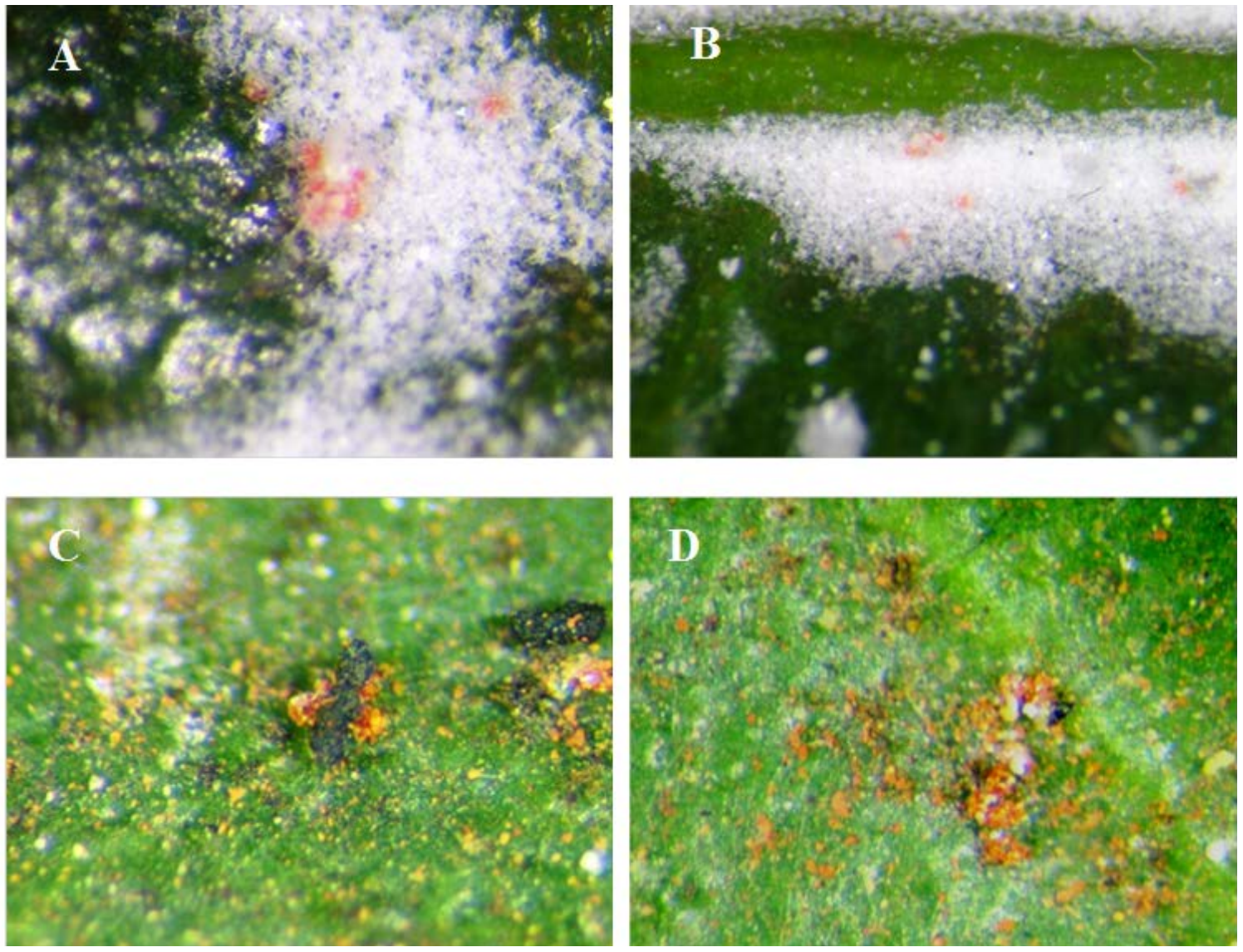

Figura 3. Postura de Brevipalpus yothersi, em arenas de criação, em laboratório, (A e B) e em folhas coletadas diretamente do campo (C e D). 

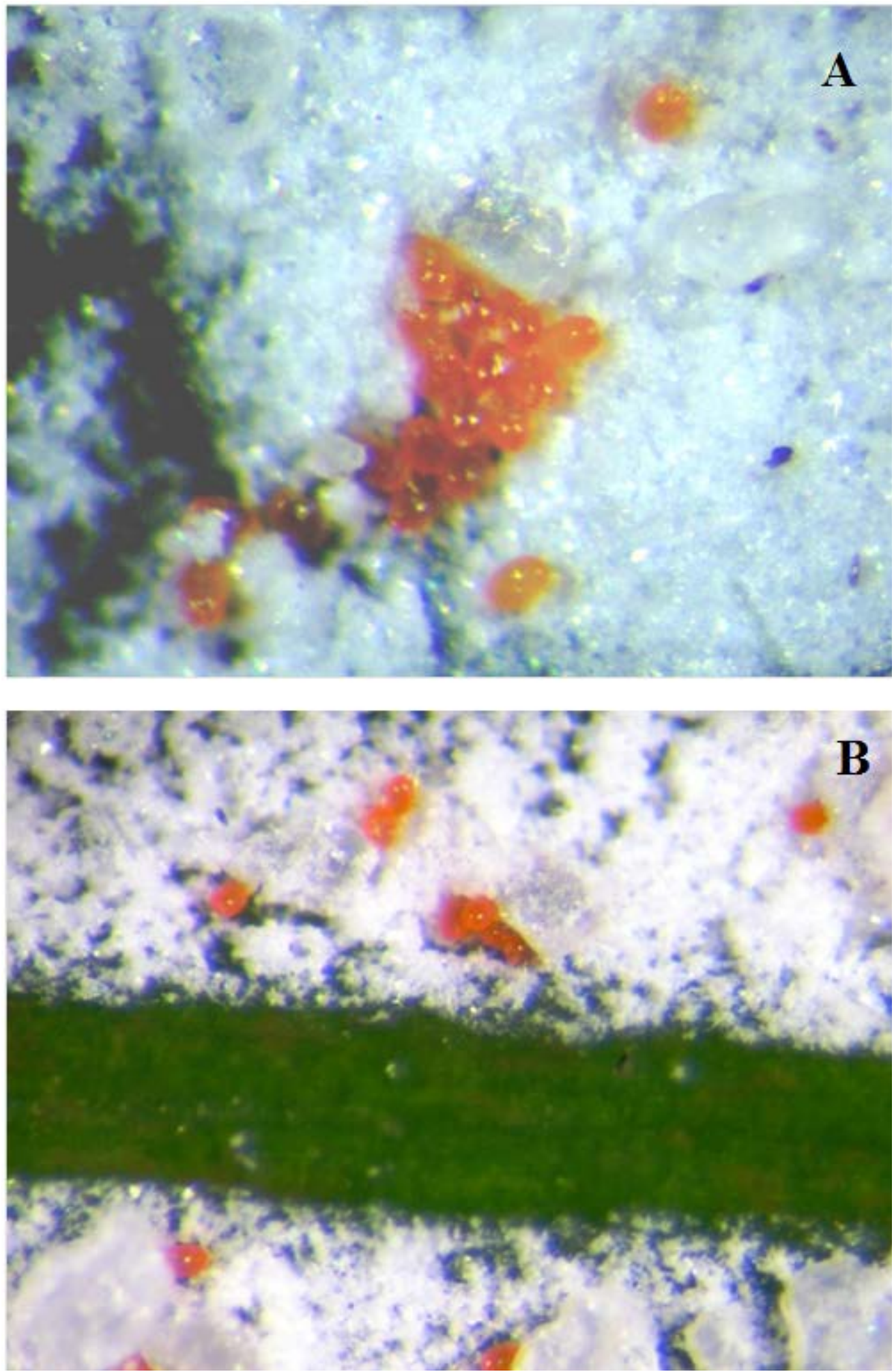

Figura 4. Postura de Brevipalpus papayensis, em arenas de criação, em laboratório. 


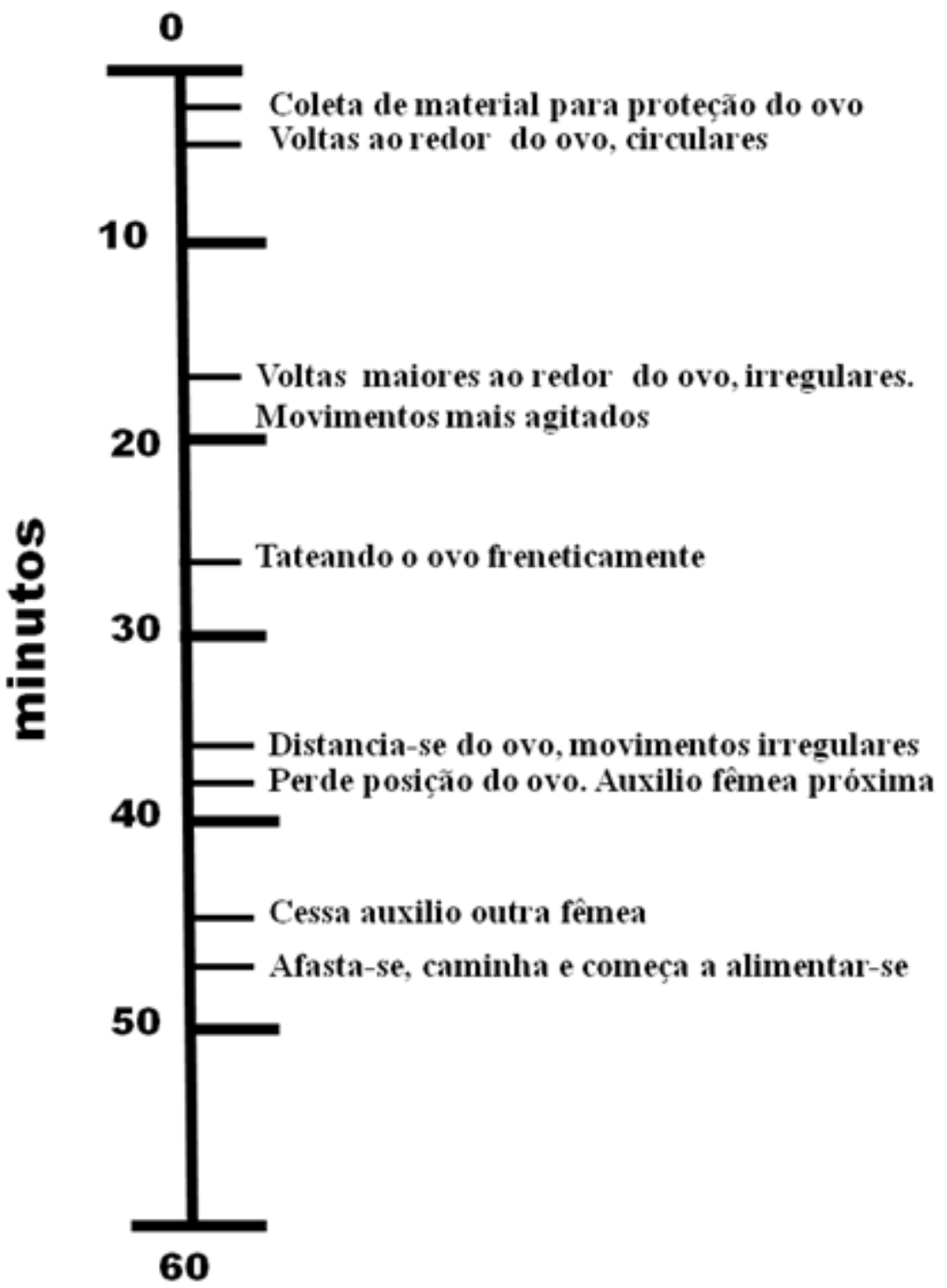

Figura 5. Comportamento de oviposição de fêmeas de Brevipalpus yothersi, em arenas de criação, em laboratório.

Recebido em: 21/03/2019

Aprovado em: 27/05/2019 